\title{
Phosphate Import at the Arbuscule: Just a Nutrient?
}

\author{
Shu-Yi Yang and Uta Paszkowski \\ University of Lausanne, Department of Plant Molecular Biology, Biophore building, CH-1015 Lausanne, Switzerland
}

Submitted 2 June 2011. Accepted 28 June 2011.

\begin{abstract}
Central to the mutualistic arbuscular mycorrhizal symbiosis is the arbuscule, the site where symbiotic phosphate is delivered. Initial investigations in legumes have led to the exciting observation that symbiotic phosphate uptake not only enhances plant growth but also regulates arbuscule dynamics and is, furthermore, required for maintenance of the symbiosis. This review evaluates the possible role of the phosphate ion, not only as a nutrient but also as a signal that is necessary for reprogramming the host cortex cell for symbiosis.
\end{abstract}

Arbuscular mycorrhizal (AM) symbioses confer a variety of benefits to plants; they enhance the plant's mineral nutrition (Smith and Read 2007) and also improve their resistance against biotic and abiotic stresses (Liu et al. 2007; Smith et al. 2010). Of these, fungal assistance in inorganic phosphate (Pi) acquisition undoubtedly represents the most pronounced advantage, resulting from the exploration of an enlarged soil volume for uptake of Pi (Smith et al. 2011). Symbiotic Pi delivery has most probably provided a selective advantage ever since the AM symbiosis evolved more than 400 million years ago and continues to do so today (Fitter 2006). Interestingly, the evolutionary origin of the AM symbiosis coincided with the occurrence of the early land plants and thereby predates the emergence of roots as plant nutrient acquisition organs (Brundrett 2002; Redecker et al. 2000; Remy et al. 1994). The development of plant root systems may, therefore, represent a secondary adaptive step to terrestrial plant life and a prerequisite for independence from symbiotic nutrient acquisition for a minor number of plant species.

Uptake of Pi across plasma membranes is commonly mediated by members of the phosphate transporter 1 (Pht1) family of proton symporters that share homology with the yeast highaffinity transporter PHO84 (Bun-Ya et al. 1991). Since the identification of the first plant Pht1 protein from Arabidopsis (Muchhal et al. 1996), a large number of related transporters have been characterized from phylogenetically diverse AM host plants (Javot et al. 2007a). Among these are high- and low-affinity transporters that are expressed in the absence of AM fungi. Their transcript levels accumulate in rhizodermal and cortical cell layers, are typically Pi-starvation inducible, and are most likely involved in direct Pi uptake from the soil into the plant cell (Ai et al. 2009; Chiou et al. 2001; Daram et al. 1998; Jia et al. 2011; C. Liu et al. 1998; H. Liu et al. 1998; Rosewarne et al. 1999). Such a role in direct Pi uptake was recently confirmed for the rice OsPT6 protein (Ai et al. 2009). When examined, transcription of these 'direct' Pi-uptake trans-

Corresponding author: Uta Paszkowski; E-mail: uta.paszkowski@unil.ch; Fax: +41216924195. porters was down-regulated during AM symbiosis, consistent with the observation that, in many plant species, symbiotic Pi acquisition dominates the direct pathway (Smith et al. 2003).

One of the foci of AM research of the past 10 years has been on better understanding of $\mathrm{Pi}$ uptake, Pi-starvation responses, and systemic Pi signaling (Javot et al. 2007a; Smith et al. 2011). The local increase of Pi levels in colonized root tissue has received less attention, and it is the aim of this review to discuss the associated consequences for nutritional as well as for symbiotic signaling.

\section{Symbiotic Pi acquisition.}

Symbiotic Pi transport occurs deep in the inner cortex of the root and is mediated by fungal haustoria, so-called arbuscules, that form inside individual host cells. Fungal arbuscules are surrounded by a plant-derived membrane and dramatically enlarge the surface area for the exchange of signals and nutrients across the peri-arbuscular interface. Extensive proliferation of the fungus within the root cortex and, simultaneously, in the soil produces an extensive syncytial hyphal network that directly connects the arbuscules with the nutrient absorbing extraradical mycelium.

The route of symbiotic Pi uptake commences at high-affinity fungal PHO84-like Pi transporters, which are expressed in the extraradical hyphae, suggesting a function in $\mathrm{Pi}$ acquisition from the soil (Benedetto et al. 2005; Harrison and van Buuren 1995; Maldonado-Mendoza et al. 2001). Inside the fungus, Pi becomes converted into polyphosphate (poly-P), which moves within the vacuolar compartment from the extra- to the intraradical mycelium (Ezawa et al. 2004; Solaiman et al. 1999). The absence of poly-P staining at the arbuscules has provided evidence for hydrolysis of poly-P and export of Pi to the periarbuscular interface (Javot et al. 2007b). From here, Pi is acquired across the peri-arbuscular membrane by distinct members of the plant Pht1 class.

\section{Candidates for the plant Pi uptake machinery.}

Candidate Pi transporters for the uptake of fungus-delivered Pi have been identified by their increased gene-expression levels in mycorrhizal relative to nonmycorrhizal control roots. Two classes have been identified, displaying either enhanced or specific accumulation of mRNA levels. The first AM-specific Pi transporters were simultaneously isolated from Medicago truncatula (MtPT4) and rice (OsPT11) (Harrison et al. 2002; Paszkowski et al. 2002), and similar proteins have also subsequently been found in other host plants (Chen et al. 2011; Karandashov and Bucher 2005; Nagy et al. 2005, 2006; Takeda et al. 2009; Wegmuller et al. 2008). Representatives of the PT4/PT11 class are conserved across mono- and dicotelydonous plant species and likely will be found in the majority of hosts of AM fungi. In contrast, AM-induced Pi transporters 
include phylogenetically diverse Pht1 proteins from different mycorrhizal plant families with no uniform distribution across the families (Table 1). In consequence, it seems that different plant families, in addition to the PT4/PT11 class, employ different Pht1 proteins during symbiosis.

\section{Plant Pi transporter mutants.}

In Medicago truncatula, MtPT4 is the only reported member of the Pht1 family displaying higher levels of mRNA following AM colonization. MtPT4 is exclusively expressed in arbusculated cells, and the gene product localizes to the periarbuscular membrane (Harrison et al. 2002). Absence of functional MtPT4 in inoculated mutant plants results in significantly lower total shoot phosphorus content, consistent with an impairment in symbiotic Pi acquisition (Javot et al. 2007b). Surprisingly, colonization levels decreased significantly in mutant relative to the wild-type roots, accompanied by the premature death of arbuscules, and ultimately, the termination of symbiosis. Detailed temporal microscopic analysis of the pre- cocious degeneration of arbuscules revealed an accelerated but, yet, morphologically regular arbuscule turnover.

No comparable knock-out has been reported from other legumes. Partial knock-down lines of the phylogenetically distant Lotus japonicus LjPT3, however, also accumulated lower amounts of phosphate in their shoots, although they produced only a quantitative and no qualitative arbuscule phenotype (Maeda et al. 2006). In addition, the development of vesicles was equivalent between mutant and wild-type plants, indicative of a viable fungus. Two RNA interference (RNAi) triggers were designed against gene-specific regions of the $L j P T 3$ gene and, therefore, LjPT4 is likely unaffected by the LjPT3 RNAi construct. At present, it remains unclear if the weaker phenotype results from a partial suppression of LjPT3 activity, from a partial reduction of symbiotic Pi import, or from LjPT3 playing a different role during symbiotic Pi import.

A null allele of the Lycopersicon esculentum LePT4, the tomato ortholog of MtPT4, did not lead to any noticeable mycorrhizal phenotype, which most likely can be attributed to

Table 1. Distribution of arbuscular mycorrhizal (AM)-associated phosphate transporter 1 proteins across mycorrhizal plant species ${ }^{\mathrm{a}}$

\begin{tabular}{|c|c|c|c|c|c|c|c|c|}
\hline Gene description & $\begin{array}{l}\text { Medicago } \\
\text { truncatula }\end{array}$ & $\begin{array}{c}\text { Lotus } \\
\text { japonicus }\end{array}$ & $\begin{array}{c}\text { Solanum } \\
\text { lycopersicum }\end{array}$ & S. tuberosum & Oryza sativa & Zea mays & $\begin{array}{l}\text { Triticum } \\
\text { aestivum }\end{array}$ & $\begin{array}{c}\text { Hordeum } \\
\text { vulgare }\end{array}$ \\
\hline PT4/PT11/PT6 & $+^{\mathrm{b}}$ & $+^{\mathrm{c}}$ & $++^{\mathrm{d}}$ & $+^{\mathrm{e}}$ & $+^{\mathrm{f}}$ & $+^{g}$ & nd & nd \\
\hline PT3 & nd & $++^{\mathrm{h}}$ & $++^{\mathrm{i}}$ & $++^{\mathrm{j}}$ & - & nd & nd & nd \\
\hline PT5 & nd & nd & $+{ }^{\mathrm{d}}$ & $+^{\mathrm{e}}$ & - & nd & nd & nd \\
\hline PT1/PT8 & nd & nd & nd & & - & nd & $+^{j}$ & $++^{\mathrm{k} .1}$ \\
\hline PT13 ${ }^{\mathrm{g}}$ & nd & nd & nd & & $t^{\mathrm{m}}$ & $t^{\mathrm{g}}$ & nd & nd \\
\hline
\end{tabular}

${ }^{\mathrm{a}} \mathrm{nd}=$ not determined, $-=$ absent from genome.

${ }^{\mathrm{b}}$ Medicago truncatula, (Harrison et al. 2002)

c Lotus japonicus (Guether et al. 2009; Takeda et al. 2009).

${ }^{\mathrm{d}}$ S. lycopersicum, (Nagy et al. 2005).

${ }^{\mathrm{e}}$ S. tuberosum (Nagy et al. 2005).

f Oryza sativa (Paszkowski et al. 2002).

${ }^{\mathrm{g}}$ Zea mays (Nagy et al. 2006).

${ }^{\mathrm{h}}$ Lotus japonicus (Maeda et al. 2006).

${ }^{i}$ S. lycopersicum (Xu et al. 2007).

j S. tuberosum, (Rausch et al. 2001).

${ }^{\mathrm{k}}$ Tritcum aestivum, (Glassop et al. 2005).

${ }^{1}$ Hordeum vulgare (Rae et al. 2003).

${ }^{\mathrm{m}}$ Oryza sativa (Guimil et al. 2005).

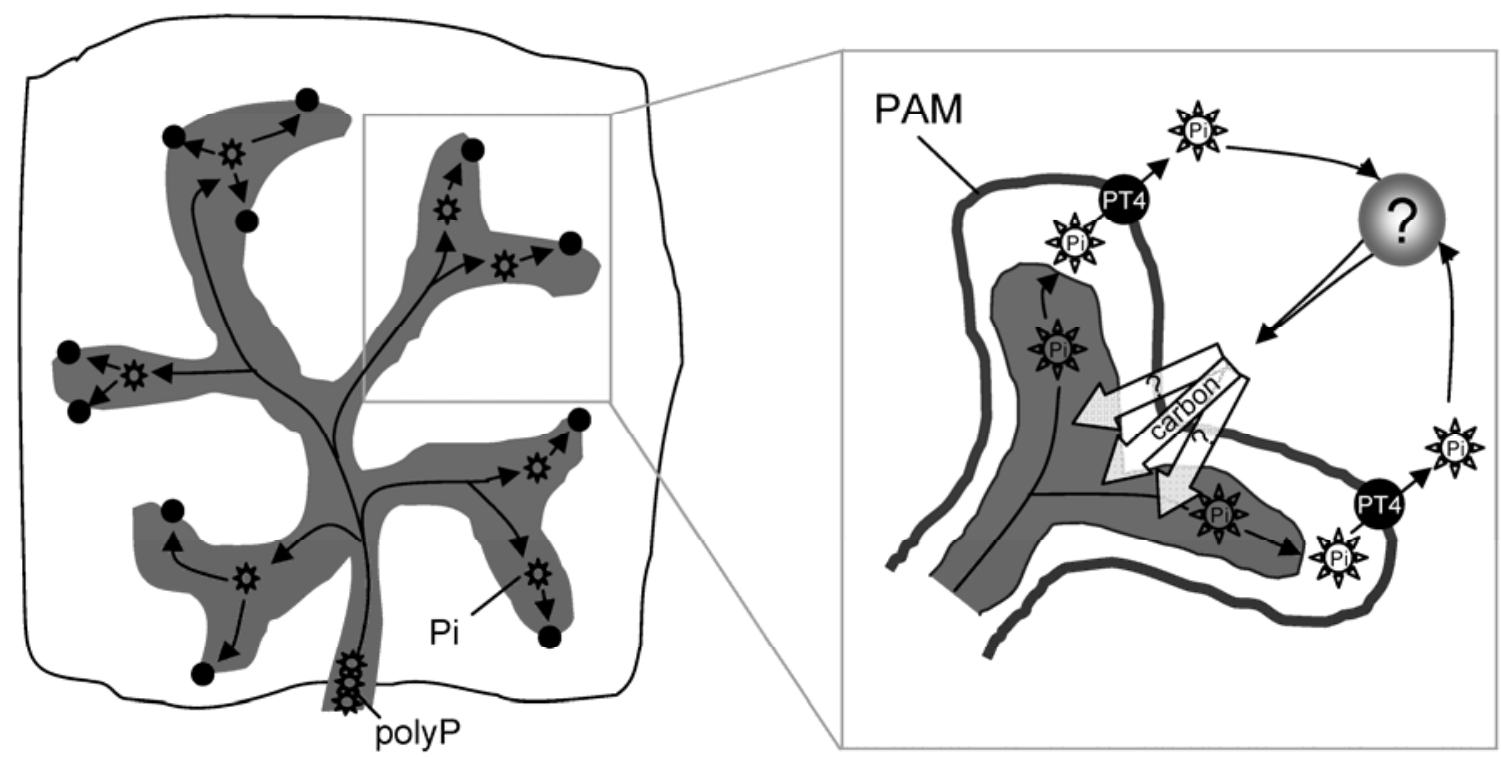

Fig. 1. Model of the symbiotically acquired inorganic phosphate (Pi) ion as a signal in arbusculated cells of wild-type plants. Polyphosphate is hydrolized inside the arbuscule and is released from the fungus by an unknown efflux mechanism. Medicago truncatula arbuscular mycorrhizal-specific Pi transporter MtPT4 is specifically localized at the peri-arbuscular membrane (PAM) of the fine branches of the arbuscule and transports Pi from the peri-arbuscular interface into the cytosol of the plant cortex cell. The Pi ion itself serves as a signal for locally high Pi levels, which stimulates the cortex cell in return to produce signals such as carbon-related compounds essential for the further development and maintenance of the arbuscule and the symbiosis. 
functional redundancy between the three AM-associated Pi transporters, LePT3, LePT4, and LePT5 (Nagy et al. 2005). On the basis of the higher accumulation of mRNA from the potato StPT3 and petunia $P h P T 3$ mRNA relative to the transcript levels of the corresponding PT4 and PT5 transporters (Nagy et al. 2005; Wegmuller et al. 2008), it is also possible that PT3 instead of PT4 represents the key player in mycorrhizal Pi import in solanaceous plant species. Understanding the role of each of the AM-induced or arbuscule-expressed $\mathrm{Pi}$ transporters and their respective coordination during symbiotic $\mathrm{Pi}$ acquisition awaits further analyses.

\section{Pi as a signal to maintain symbiosis.}

Analysis of the null allele of MtPT4, in conjunction with the respective RNAi alleles, clearly demonstrated that symbiotic $\mathrm{Pi}$ import is crucial for wild-type arbuscule dynamics and progression of colonization, suggesting that it is the Pi ion itself that serves as a local signal and triggers the reprogramming of the plant cell for supporting the fungus (Fig. 1). The flow of $\mathrm{Pi}$ across the peri-arbuscular cortex membrane might be a mechanism to distinguish AM fungi from less beneficial microbial invaders and, hence, committed sugar investment is safe (Fitter 2006; Javot et al. 2007b). The lack of symbiotically delivered Pi might prompt the plant to generate an unsustainable environment, thus to reject the fungus. Possible mechanisms for rejection might include reducing carbon flow to the peri-arbuscular interface to starve the fungus or, alternatively, repression of noncarbon-related signals required to maintain normal fungal colonization.

It has been observed that transcript accumulation for sucrose-cleaving sucrose synthase genes increases around arbuscules (Baier et al. 2010; Blee and Anderson 2002; Hohnjec et al. 2003; Ravnskov et al. 2003). Moreover, RNAi-mediated suppression of endogenous sucrose synthase gene expression is sufficient to abolish arbuscule maturation and further intraradical fungal growth in Medicago truncatula (Baier et al. 2010) and, thus, reproduces the mtpt4 phenotype (Javot et al. 2007b). This phenotypic resemblance provides strong support for an altered carbon flow affecting fungal growth in the mtpt4 mutant, and it remains to be determined whether malnutrition or 'miscommunication' leads to fungal death.

Further support for a connection between $\mathrm{Pi}$ and carbon fluxes is provided by the fact that plant roots have the capacity to respond to local Pi availability, as illustrated by the proliferation of lateral roots specifically into Pi-rich soil patches (Drew 1975; Linkohr et al. 2002). Plant roots precisely monitor locally elevated $\mathrm{Pi}$ levels in the soil substrate and transduce this information into a morphological and physiological response that redirects sugars to specific parts of the root system to promote growth. Interestingly, in addition to $\mathrm{Pi}$, ammonium and nitrate (but not potassium) can also promote localized enhancement of lateral root growth (Drew 1975), arguing for the existence of converging signal transduction beyond the primary specific detection of diverse ions that results in the same morphological consequences. For nitrate, it is well-established that it is the ion itself that acts as a signal, rather than as an indirect nutrient effect that stimulates lateral roots (Zhang and Forde 1998, 2000). Pi may well act as a local signal in a related way. Similarly, since AM fungi colonize roots in a nonsynchronous, patchy fashion, symbiotic Pi delivery and concomitantly increased cellular Pi levels occur heterogeneously only in those regions of the root in which arbuscules form (Cox and Tinker 1976). In turn, carbon distribution might be channeled towards arbusculated cortex tissue (Fig. 1). Therefore, Pi-stimulated carbon allocation mechanisms might be commonly shared between the AM symbiosis and the phenomenon of locally Pi- (and other nutrient-) induced lateral root proliferation (Fitter 2006).

\section{Conclusions.}

Although arbuscules have long been recognized as the 'heart' of the AM symbiosis, the mechanisms associated with bidirectional nutrient exchange are still largely elusive. It has become evident that import of the Pi ion across the peri-arbuscular interface provides an essential signal for sustaining intraradical fungal development, possibly via redirecting photosynthates towards the arbuscule. This mechanism is likely as old as the symbiosis itself and, following the evolution of the roots, may have been adapted to adjust root system architecture to fluctuating Pi and other nutrient sources in the soil.

\section{ACKNOWLEDGMENTS}

We are very grateful to $\mathrm{R}$. Sawers for carefully reading the manuscript. S.-Y. Yang was supported by a grant from National Center for Competence in Research: "Plant Survival" and U. Paszkowski by the Swiss National Science Foundation "Professeur Boursier" grant PP00A-110874.

\section{LITERATURE CITED}

Ai, P., Sun, S., Zhao, J., Fan, X., Xin, W., Guo, Q., Yu, L., Shen, Q., Wu, P., Miller, A. J., and $\mathrm{Xu}, \mathrm{G} .2009$. Two rice phosphate transporters, OsPht $1 ; 2$ and OsPht $1 ; 6$, have different functions and kinetic properties in uptake and translocation. Plant J. 57:798-809.

Baier, M. C., Keck, M., Godde, V., Niehaus, K., Kuster, H., and Hohnjec, N. 2010. Knockdown of the symbiotic sucrose synthase MtSucS1 affects arbuscule maturation and maintenance in mycorrhizal roots of Medicago truncatula. Plant Physiol. 152:1000-1014.

Benedetto, A., Magurno, F., Bonfante, P., and Lanfranco, L. 2005. Expression profiles of a phosphate transporter gene (GmosPT) from the endomycorrhizal fungus Glomus mosseae. Mycorrhiza 15:620-627.

Blee, K. A., and Anderson, A. J. 2002. Transcripts for genes encoding soluble acid invertase and sucrose synthase accumulate in root tip and cortical cells containing mycorrhizal arbuscules. Plant Mol. Biol. 50:197-211.

Brundrett, M. 2002. Coevolution of roots and mycorhizzas of land plants. New Phytol. 154:275-304.

Bun-Ya, M., Nishimura, M., Harashima, S., and Oshima, Y. 1991. The PHO84 gene of Saccharomyces cerevisiae encodes an inorganic phosphate transporter. Mol. Cell Biol. 11:3229-3238.

Chen, A., Gu, M., Sun, S., Zhu, L., Hong, S., and Xu, G. 2011. Identification of two conserved cis-acting elements, MYCS and P1BS, involved in the regulation of mycorrhiza-activated phosphate transporters in eudicot species. New Phytol. 189:1157-1169.

Chiou, T. J., Liu, H., and Harrison, M. J. 2001. The spatial expression patterns of a phosphate transporter (MtPT1) from Medicago truncatula indicate a role in phosphate transport at the root/soil interface. Plant $\mathrm{J}$. 25:281-293.

Cox, G., and Tinker, P. 1976. Translocation and transfer of nutrients in vesicular-arbuscular mycorrhizas. 1. Arbuscule and phosphorus transfer-quantitative ultrastructural study. New Phytol. 77:371-378.

Daram, P., Brunner, S., Persson, B.L., Amrhein, N., and Bucher, M. 1998. Functional analysis and cell-specific expression of a phosphate transporter from tomato. Planta 206:225-233.

Drew, M. 1975. Comparison of the effects of a localized supply of phosphate, nitrate, ammonium and potassium on growth of seminal root system, and shoot, of barley. New Phytol. 75:479-490.

Ezawa, T., Cavagnaro, T., Smith, S., Smith, F., and Ohtomo, R. 2004. Rapid accumulation of polyphosphate in extraradical hyphae of an arbsucular mycorrhizal fungus as revealed by histochemistry and polyphosphatekinase/luciferase system. New Phytol. 161:387-392.

Fitter, A. H. 2006. What is the link between carbon and phosphorous fluxes in arbuscular mycorrhizas? A null hypothesis for symbiotic function. New Phytol. 172:3-6.

Glassop, D., Smith, S. E., and Smith, F. W. 2005. Cereal phosphate transporters associated with the mycorrhizal pathway of phosphate uptake into roots. Planta 222:688-698.

Guether, M., Balestrini, R., Hannah, M., He, J., Udvardi, M. K., and Bonfante, P. 2009. Genome-wide reprogramming of regulatory networks, transport, cell wall and membrane biogenesis during arbuscular mycorrhizal symbiosis in Lotus japonicus. New Phytol. 182:200-212.

Güimil, S., Chang, H., Zhu, T., Sesma, A., Osbourn, A., Roux, C., Ioannidis, V., Oakely, E. J., Docquier, M., Descombes, P., Briggs, S. P., and Paszkowski, U. 2005. Comparative transcriptomics of rice reveals an ancient pattern of response to microbial colonization. Proc. Natl. 
Acad. Sci. U.S.A. 102:8066-8070.

Harrison, M. J., and van Buuren, M. L. 1995. A phosphate transporter from the mycorrhizal fungus Glomus versiforme. Nature 378:626-629.

Harrison, M. J., Dewbre, G. R., and Liu, J. 2002. A phosphate transporter from Medicago truncatula involved in the acquisition of phosphate released by arbuscular mycorrhizal fungi. Plant Cell 14:2413-2429.

Hohnjec, N., Perlick, A. M., Puhler, A., and Kuster, H. 2003. The Medicago truncatula sucrose synthase gene MtSucS1 is activated both in the infected region of root nodules and in the cortex of roots colonized by arbuscular mycorrhizal fungi. Mol. Plant-Microbe Interact. 16:903-915.

Javot, H., Pumplin, N., and Harrison, M. 2007a. Phosphate in the arbuscular mycorrhizal symbiosis: transport properties and regulatory roles. Plant Cell Environ. 30:310-322.

Javot, H., Varma Penmetsa, R., Terzaghi, N., Cook, D. R., and Harrison, M. J. 2007b. A Medicago truncatula phosphate transporter indispensible for the arbuscular mycorrhizal symbiosis. Proc. Natl. Acad. Sci. U.S.A. 104:1720-1725.

Jia, H., Ren, H., Gu, M., Zhao, J., Sun, S., Chen, J., Wu, P., and Xu, G. 2011. The phosphate transporter gene, OsPht 1;8, is involved in phosphate homeostasis in rice. Plant Physiol. 156:1164-1175

Karandashov, V., and Bucher, M. 2005. Symbiotic phosphate transport in arbuscular mycorrhizas. Trends Plant Sci 10:22-29.

Linkohr, B. I., Williamson, L. C., Fitter, A. H., and Leyser, H. M. 2002. Nitrate and phosphate availability and distribution have different effects on root system architecture of Arabidopsis. Plant J. 29:751-760.

Liu, C., Muchhal, U. S., Uthappa, M., Kononowicz, A. K., and Raghothama, K. G. 1998. Tomato phosphate transporter genes are differentially regulated in plant tissues by phosphorus. Plant Physiol. 116:91-99.

Liu, H., Trieu, A. T., Blaylock, L. A., and Harrison, M. J. 1998. Cloning and characterization of two phosphate transporters from Medicago truncatula roots: regulation in response to phosphate and to colonization by arbuscular mycorrhizal (AM) fungi. Mol. Plant-Microbe Interact. $11: 14-22$.

Liu, J., Maldonado-Mendoza, I., Lopez-Meyer, M., Cheung, F., Town, C. D., and Harrison, M. J. 2007. Arbuscular mycorrhizal symbiosis is accompanied by local and systemic alterations in gene expression and an increase in disease resistance in the shoots. Plant J. 50:529-544.

Maeda, D., Ashida, K., Iguchi, K., Chechetka, S., Hijikata, A., Okusako, Y., Deguchi, Y., Izui, K., and Hata, S. 2006. Knockdown of an arbuscular mycorrhiza-inducible phosphate transporter gene of Lotus japonicus suppresses mutualistic symbiosis. Plant Cell Physiol. 47:807-817.

Maldonado-Mendoza, I. E., Dewbre, G. R., and Harrison, M. J. 2001. A phosphate transporter gene from the extra-radical mycelium of an arbuscular mycorrhizal fungus Glomus intraradices is regulated in response to phosphate in the environment. Mol. Plant-Microbe Interact. 14:1140-1148

Muchhal, U. S., Pardo, J. M., and Raghothama, K. G. 1996. Phosphate transporters from the higher plant Arabidopsis thaliana. Proc. Natl. Acad. Sci. U.S.A. 93:10519-10523.

Nagy, R., Karandashov, V., Chague, V., Kalinkevich, K., Tamasloukht, M., Xu, G., Jakobsen, I., Levy, A. A., Amrhein, N., and Bucher, M. 2005. The characterization of novel mycorrhiza-specific phosphate transporters from Lycopersicon esculentum and Solanum tuberosum uncovers functional redundancy in symbiotic phosphate transport in solanaceous species. Plant J. 42:236-250.

Nagy, R., Vasconcelos, M. J. V., Zhao, S., McElver, J., Bruce, W. Amrhein, N., Raghothama, K. G., and Bucher, M. 2006. Differential regulation of five Pht 1 phosphate transporters from maize (Zea mays L.). Plant Biol 8:186-197.

Paszkowski, U., Kroken, S., Roux, C., and Briggs, S. 2002. Rice phosphate transporters include an evolutionarily divergent gene specifically activated in arbuscular mycorrhizal symbiosis. Proc. Natl. Acad. Sci. U.S.A.99:13324-13329.

Rae, A. L., Cybinski, D. H., Jarmey, J. M., and Smith, F. W. 2003. Characterization of two phosphate transporters from barley; evidence for diverse function and kinetic properties among members of the Pht 1 family. Plant Mol. Biol. 53:27-36.

Rausch, C., Daram, P., Brunner, S., Jansa, J., Laloi, M., Leggewie, G., Amrhein, N., and Bucher, M. 2001. A phosphate transporter expressed in arbuscule-containing cells in potato. Nature 414:462-470.

Ravnskov, S., Wu, Y., and Graham, J. 2003. Arbuscular mycorrhizal fungi differentially affect expression of genes coding for sucrose synthases in maize roots. New Phytol. 157:539-545.

Redecker, D., Kodner, R., and Graham, L. E. 2000. Glomalean fungi from the Ordovician. Science 289:1920-1921.

Remy, W., Taylor, T. N., Hass, H., and Kerp, H. 1994. Four hundredmillion-year-old vesicular arbuscular mycorrhizae. Proc. Natl. Acad. Sci. U.S.A. 91:11841-11843.

Rosewarne, G., Barker, S., Smith, S., Smith, F., and Schachtman, D. 1999. A lycopersicon esculentum phosphate transporter (LePT1) involved in phosphorus uptake from a vesicular-arbuscular mycorhizal fungus. New Phytol. 144:507-516.

Smith, S., and Read, D. 2007. Mycorrhizal Symbiosis. Academic Press, London.

Smith, S. E., Smith, F. A., and Jakobsen, I. 2003. Mycorrhizal fungi can dominate phosphate supply to plants irrespective of growth responses. Plant Physiol. 133:16-20.

Smith, S., FAcelli, E., Pope, S., and Smith, F. 2010. Plant performance in stressful environments: interpreting new and established knowledge of the roles of arbuscular mycorrhizas. Plant Soil 326:3-20.

Smith, S. E., Jakobsen, I., Groenlund, M., and Smith, F. A. 2011. Roles of arbuscular mycorrhizas in plant phosphorus nutrition: Interactions between pathways of phosphorus uptake in arbuscular mycorrhizal roots have important implications for understanding and manipulating plant phosphorus acquisition. Plant Physiol. 156:1050-1057.

Solaiman, M. Z., Ezawa, T., Kojima, T., and Saito, M. 1999. Polyphosphates in intraradical and extraradical hyphae of an arbuscular mycorrhizal fungus, Gigaspora margarita. Appl Environ Microbiol 65:56045606.

Takeda, N., Sato, S., Asamizu, E., Tabata, S., and Parniske, M. 2009. Apoplastic plant subtilases support arbuscular mycorrhiza development in Lotus japonicus. Plant J. 58:766-777.

Wegmuller, S., Svistoonoff, S., Reinhardt, D., Stuurman, J., Amrhein, N., and Bucher, M. 2008. A transgenic dTph1 insertional mutagenesis system for forward genetics in mycorrhizal phosphate transport of Petunia. Plant J. 54:1115-1127.

Xu, G. H., Chague, V., Melamed-Bessudo, C., Kapulnik, Y., Jain, A., Raghothama, K. G., Levy, A. A., and Silber, A. 2007. Functional characterization of LePT4: A phosphate transporter in tomato with mycorrhiza-enhanced expression. J. Exp. Bot. 58:2491-2501.

Zhang, H., and Forde, B. G. 1998. An Arabidopsis MADS box gene that controls nutrient-induced changes in root architecture. Science 279:407409.

Zhang, H., and Forde, B. G. 2000. Regulation of Arabidopsis root development by nitrate availability. J. Exp. Bot. 51:51-59. 